\title{
Radiation in the treatment of liver cancer
}

\section{A review of the literature}

Laura Callan (Meds 2015), Benjamin Beech (Meds 2016), Eugene Wong (PhD, FCCPM)

Faculty Reviewer: Dr Michael Lock, MD, CCFP, FRCP, FRCPC, Chair (Department of Oncology, Division of

Radiation Oncology)

Radiation therapy (RT) is a newly evolving option in the treatment of both primary and metastatic liver cancer. To understand how RT can be applied to liver cancer and potential future directions of treatments, a review of the literature was performed.

\section{INTRODUCTION \& GENERAL TREATMENT OVERVIEW}

\section{PRIMARY LIVER CANCER}

Primary liver cancer is the fastest growing cancer in Canada, with the incidence rate increasing by almost $4 \%$ per year in males and $3 \%$ per year in females since 1970, and is the third most common cause of cancer death worldwide. ${ }^{1}$ The most common type of primary liver cancer is hepatocellular carcinoma (HCC), accounting for approximately $72 \%$ of cases. ${ }^{1}$ Hepatitis B and C viruses (HBV and $\mathrm{HCV}$ ) are known to be oncogenic ${ }^{1}$ and it is possible that some of the increase in the rates of liver cancer in North America is a result of increased immigration from countries where HBV is endemic; ${ }^{2}$ however, half of all cases of HCC in North America are not related to $\mathrm{HBV}$ or $\mathrm{HCV}^{3}$ Other risk factors include alcohol, ${ }^{4}$ obesity, ${ }^{5}$ diabetes, ${ }^{6}$ smoking ${ }^{7}$ and genetic risk factors such as hemochromatosis and alphal-antitrypsin deficiency. ${ }^{8}$ Primary liver cancer is one of the deadliest cancers, with a $20 \%$ five-year survival. ${ }^{1}$

The only treatments of liver cancer currently considered potentially curative are resection, transplantation, ${ }^{9}$ transarterial chemoembolization (TACE) ${ }^{10}$ and radiofrequency ablation (RFA).,11 In 2008, a chemotherapeutic agent, sorafenib, was shown to be tolerable and effective in a select group of patients. ${ }^{12}$ Patients with very early-stage primary liver cancer are typically treated with surgical resection, resulting in a $90 \%$ five-year survival rate. ${ }^{14}$ Resection can also be used in patients with early-stage disease and good liver function (Child-Pugh A), ${ }^{1}$ resulting in a 50\% five-year survival rate; however, these patients still have a $70 \%$ recurrence rate. ${ }^{15}$ Resection is not an option for patients with early-stage disease and poor liver function, so they are often treated with liver transplantation, ${ }^{1}$ resulting in a 70\% five-year survival rate and a recurrence rate of less than $15 \% ;{ }^{15}$ unfortunately, the wait time for such a surgery is typically very long. Other patients with early-stage disease for whom surgery is not possible due to the location of the tumour can be treated with RFA, ${ }^{1}$ which has similar survival rates to resection. ${ }^{16}$ TACE is often used to treat intermediate-stage liver cancer and has been shown to improve survival by 20 to $25 \%,{ }^{14}$ with the best results occurring when there is no macrovascular involvement ${ }^{10,17}$ and a tumour size less than $10 \mathrm{~cm} .{ }^{18}$ Those with advanced disease are typically not treated actively, ${ }^{1}$ the exception being the relatively uncommon case where the patient retains good liver function and sorafenib may be used. ${ }^{14}$ Two randomized controlled trials with sorafenib have shown that median survival is improved by two to three months. ${ }^{12}$

\section{LIVER METASTASES}

The most common causes of secondary hepatic malignancy are colorectal carcinoma, breast carcinoma, melanoma and neuroendocrine tumours. ${ }^{15}$ The 5 -year overall survival with unresectable liver metastases from colorectal cancer is less than $2 \%$ when treated with chemotherapy. ${ }^{15}$ If local therapy, such as surgical resection or RFA, is possible, survival increases to between 33 to $58 \%{ }^{19-21}$ and 17 to $55 \%{ }^{15}$ respectively. Therefore, resection and preservation of a minimal functional remnant of liver is recommended. ${ }^{21}$ If the tumours are originally unresectable, it is sometimes possible to use chemotherapy to shrink the tumours to a resectable size or away from critical structures such as blood vessels. ${ }^{15}$

\section{NOVEL TREATMENT METHODS FOR LIVER CANCER}

Many novel approaches to improving survival in both primary and secondary liver cancer have been investigated. Radioembolization, the delivery of radioactive particles to a tumour via the bloodstream, has shown limited success in causing tumour necrosis, thereby improving survival. ${ }^{22}$ Biodegradeable microspheres full of a chemotherapeutic agent may also be used and this technique has been shown to be safer than traditional chemotherapy in patients with liver disease; however, there is no evidence to date that it improves survival compared to other traditional treatment options. ${ }^{23}$ Another approach has been to use radiotherapy, a treatment frequently employed for cancers in other locations, but, for reasons described below, it has only recently been used with curative intent in patients with liver cancer. Radiation is appealing as it is non-invasive and has been shown to be effective in the primary cancers that commonly metastasize to the liver. Furthermore, it has been shown to improve survival in patients who cannot receive other therapies due to complications such as portal vein thrombosis. ${ }^{24}$

\section{LIVER TOXICITY IN RADIOTHERAPY}

Irradiating the liver can lead to radiation-induced liver disease (RILD) even at low doses. A whole-liver tolerance dose has been set at a maximum of $30 \mathrm{~Gy}$ in separate 2 Gy fractions, a dose which results in a $5 \%$ risk of liver failure 5 years after treatment. ${ }^{25}$ RILD is potentially life-threatening and in the past has limited the role of radiation in liver cancer to mostly palliative. ${ }^{26-29}$ This risk of RILD increases if the patient has established poor liver function due to cirrhosis or the cancer itself. ${ }^{28,30}$ Malignant lesions of the liver typically require greater than 75 Gy for adequate treatment ${ }^{31}$ and, therefore, treatment of these lesions with radiation poses a very high risk of 


\section{FEATURE ARTICLE}

RILD. Since the liver has regenerative properties, it is possible to irradiate a portion of the liver, rather than the entire organ, thereby decreasing the risk of RILD; ${ }^{32,33}$ however, until recently the technology required to locate the tumour within the liver and to apply radiation to that limited area has not been available.

\section{TECHNICAL ADVANCES WHICH ALLOW FOR RADIOTHERAPY WITH CURATIVE INTENT}

\section{IMAGING METHODS}

Recent advancements have allowed the use of radiation in liver cancer with curative intent. New imaging techniques can better localize the tumour within the liver, allowing for high doses to be applied to a small area around the focal lesion and limiting the risk of RILD to less than $5 \%{ }^{34-38}$ These include the use of contrast-enhanced computed tomography $(\mathrm{CT})^{39}$ as well as combined imaging techniques such as CT with magnetic resonance imaging (MRI) or positron emission tomography (PET) to better define tumour boundaries. ${ }^{40,41}$ Further, imaging can now be performed in the treatment room, using technology such as cone beam CT to allow for visualization of the liver immediately before or during treatment. ${ }^{45}$

\section{MOTION INCORPORATING METHODS}

Methods for reducing or accounting for liver motion can be applied during imaging to improve the quality of the image or during treatment to allow for more precise delivery. During breathing, the liver moves on average $15.5 \mathrm{~mm}$ in the craniocaudal direction, $10 \mathrm{~mm}$ in the anteroposterior direction and $7.5 \mathrm{~mm}$ in the mediolateral direction. ${ }^{46}$ It is recommended that treatment planning account for any motion greater than $5 \mathrm{~mm} .{ }^{47}$ This can be done by three methods: reducing motion through abdominal compression, eliminating motion through breath holding or incorporating motion through gating or tracking of surrogate markers. ${ }^{45}$ Abdominal compression requires the patient to voluntarily breathe shallowly while the abdomen is mechanically compressed, ${ }^{45}$ and can reduce liver motion by approximately $7 \mathrm{~mm} .{ }^{48}$ Eliminating motion through breath-holding is most reproducible if patients hold their breath at the exhale position ${ }^{45}$ and has an interfraction variability of $2.2 \mathrm{~mm}$ $+/-2.0 \mathrm{~mm} .^{49,50}$ Incorporating motion into treatment is currently the focus of extensive research as it reduces the burden on the patient. ${ }^{45}$ Relevant techniques include gating, where the radiation beam is only turned on when the tumour is in a specific position, and tracking, where the beam is moved according to the position of the tumour. Both require tracking the position of the tumour with either an external marker placed on the patient's chest, or a fiducial marker placed within the patient's liver. ${ }^{51}$

\section{DOSE DELIVERY METHODS}

Advances in methods of delivering radiation have also allowed for more precise dose delivery. Conformal RT (CRT), intensity-modulated RT (IMRT) and stereotactic ablative RT (SABR) have allowed for a higher dose to be delivered to a focal tumour even while a lower dose is delivered to the surrounding liver and other normal structures. ${ }^{52-54} \mathrm{CRT}$ utilizes multiple beams to sculpt the dose to conform to the shape of tumours. IMRT advances this technique by using computer algorithms to enable even more accurate placement of radiation dose within the tumour. SABR uses image guidance and increased dose per treatment fraction to ablate tumours. Studies have shown that the most important predictor of survival for liver cancer is radiation dose. ${ }^{31}$ Treating a tumour with more than 75 Gy overall has been shown to increase mean survival from 14.9 months to 23.9 months in $\mathrm{HCC} ;{ }^{31}$ however, no randomized trials have been performed to date.

\section{COMBINATION TREATMENT METHODS}

A further technique is to combine other treatment modalities with RT. The most common treatment used in such a combination is TACE. ${ }^{55-59}$ Studies have found that it is sometimes possible to shrink the tumour using TACE, then irradiate the smaller liver volume. ${ }^{31}$ A higher overall survival rate has been found with the combination of radiation and TACE versus TACE alone (11.7 compared to 4.7 months median overall survival). ${ }^{60}$

\section{CONCLUSIONS AND FUTURE DIRECTIONS}

Despite statistically significant mortality improvements in primary and secondary liver cancer as a result of the above, the overall outcome for a large proportion of patients remains poor. Major advancements in radiation technology have resulted in better motion control, tumour localization, understanding of radiobiological toxicity and radiation delivery. Case series data suggests that this has translated into improved local control and survival. These early studies have suggested particular roles for radiation that require additional investigation, including the role of radiation in patients (1) with larger lesions when combined with TACE, (2) being bridged to transplant, (3) with portal vein thrombosis and (4) undergoing palliation.

\section{REFERENCES}

1. Canadian Cancer Society's Advisory Committee on Cancer Statistics. Canadian cancer statistics 2013. Toronto, ON: Canadian Cancer Society; 2013.

2. Burak KW, Coffin CS, Myers RP. Hepatitis B awareness and education: a failing grade. Can J Gastroenterol. 2011;25(3):125-6.

3. El-Serag HB, Mason AC. Risk factors for the rising rates of primary liver cancer in the United States. Arch Intern Med. 2000;160(21):3227-30.

4. Corrao G, Bagnardi V, Zambon A, La Vecchia C. A meta-analysis of alcohol consumption and the risk of 15 diseases. Prev Med. 2004;38(5):613-9.

5. Larsson SC, Wolk A. Overweight, obesity and risk of liver cancer: a meta-analysis of cohort studies. Br J Cancer. 2007;97(7):1005-8.

6. El-Serag HB, Hampel H, Javadi F. The association between diabetes and hepatocellular carcinoma: a systematic review of epidemiologic evidence. Clin Gastroenterol Hepatol. 2006;4(3):369-80.

7. Gandini S, Botteri E, Iodice S, et al. Tobacco smoking and cancer: a meta-analysis. Int J Cancer. 2008;122(1):155-64 


\section{FEATURE ARTICLE}

8. Blonski W, Kotlyar DS, Forde KA. Non-viral causes of hepatocellular carcinoma. World J Gastroenterol. 2010;16(29):3603-15.

9. Mazzaferro V, Regalia E, Doci R, et al. Liver transplantation for the treatment of small hepatocellular carcinomas in patients with cirrhosis. N Engl J Med. 1996;334(11):693-9.

10. Llovet JM, Real MI, Montana X, et al. Arterial embolisation or chemoembolisation versus symptomatic treatment in patients with unresectable hepatocellular carcinoma: a randomised controlled trial. Lancet. 2002;359(9319):1734-9.

11. Sherman M, Burak K, Maroun J, et al. Multidisciplinary Canadian consensus recommendations for the management and treatment of hepatocellular carcinoma. Curr Oncol. 2011;18(5):22840.

12. Llovet JM, Ricci S, Mazzaferro V, et al. Sorafenib in advanced hepatocellular carcinoma. N Engl J Med. 2008;359(4):378-90.

13. Livraghi T, Meloni F, Di Stasi M, et al. Sustained complete response and complications rates after radiofrequency ablation of very early hepatocellular carcinoma in cirrhosis: is resection still the treatment of choice? Hepatology. 2008;47(1):82-9.

14. El-Serag HB. Hepatocellular carcinoma. N Engl J Med. 2011;365(12):1118-1127.

15. Dawson LA. Overview: where does radiation therapy fit in the spectrum of liver cancer local-regional therapies? Semin Radiat Oncol. 2011;21(4):241-6.

16. Hong SN, Lee SY, Choi MS, et al. Comparing the outcomes of radiofrequency ablation and surgery in patients with a single small hepatocellular carcinoma and well-preserved hepatic function. J Clin Gastroenterol. 2005;39(3):247-52.

17. Lo CM, Ngan H, Tso WK, et al. Randomized controlled trial of transarterial lipiodol chemoembolization for unresectable hepatocellular carcinoma. Hepatology. 2002;35(5):1164-71.

18. Thornton RH, Covey A, Petre EN, et al. A comparison of outcomes from treating hepatocellular carcinoma by hepatic artery embolization in patients younger or older than 70 years. Cancer. 2009;115(21):5000-6.

19. Wei AC, Greig PD, Grant D, Taylor B, Langer B, Gallinger S. Survival after hepatic resection for colorectal metastases: a 10-year experience. Ann Surg Oncol. 2006;13(5):668-76.

20. Lo SS, Moffatt-Bruce SD, Dawson LA, et al. The role of local therapy in the management of lung and liver oligometastases. Nat Rev Clin Oncol. 2011;8(7):405-16.

21. Fong Y, Fortner J, Sun RL, Brennan MF, Blumgart LH. Clinical score for predicting recurrence after hepatic resection for metastatic colorectal cancer: analysis of 1001 consecutive cases. Ann Surg. 1999;230(3):309-18; discussion 318-21.

22. Memon K, Kulik L, Lewandowski RJ, et al. Radiographic response to locoregional therapy in hepatocellular carcinoma predicts patient survival times. Gastroenterology. 2011;141(2):52635, 535.el-2.

23. Lammer J, Malagari K, Vogl T, et al. Prospective randomized study of doxorubicin-eluting-bead embolization in the treatment of hepatocellular carcinoma: results of the PRECISION V study. Cardiovasc Intervent Radiol. 2010;33(1):41-52.

24. Zhang XB, Wang JH, Yan ZP, Qian S, Du SS, Zeng ZC. Hepatocellular carcinoma with main portal vein tumor thrombus: treatment with 3-dimensional conformal radiotherapy after portal vein stenting and transarterial chemoembolization. Cancer. 2009;115(6):1245-52.

25. Emami B, Lyman J, Brown A, et al. Tolerance of normal tissue to therapeutic irradiation. Int J Radiat Oncol Biol Phys. 1991;21(1):109-22.

26. Dawson LA, Ten Haken RK. Partial volume tolerance of the liver to radiation. Semin Radiat Oncol. 2005;15(4):279-83.

27. Reed GB,Jr, Cox AJ,Jr. The human liver after radiation injury, a form of veno-occlusive disease. Am J Pathol. 1966;48(4):597-611.

28. Xu ZY, Liang SX, Zhu J, et al. Prediction of radiation-induced liver disease by lyman normal-tissue complication probability model in three-dimensional conformal radiation therapy for primary liver carcinoma. Int J Radiat Oncol Biol Phys. 2006;65(1):189-95.

29. Liang SX, Zhu XD, Lu HJ, et al. Hypofractionated three-dimensional conformal radiation therapy for primary liver carcinoma. Cancer. 2005;103(10):2181-8.

30. Liang SX, Zhu XD, Xu ZY, et al. Radiation-induced liver disease in three-dimensional conformal radiation therapy for primary liver carcinoma: the risk factors and hepatic radiation tolerance. Int J Radiat Oncol Biol Phys. 2006;65(2):426-34.

31. Feng M, Ben-Josef E. Radiation therapy for hepatocellular carcinoma. Semin Radiat Oncol. 2011;21(4):271-7.

32. Son SH, Choi BO, Ryu MR, et al. Stereotactic body radiotherapy for patients with unresectable primary hepatocellular carcinoma: dose-volumetric parameters predicting the hepatic complication. Int J Radiat Oncol Biol Phys. 2010;78(4):1073-80.

33. Schefter TE, Kavanagh BD, Timmerman RD, Cardenes HR, Baron A, Gaspar LE. A phase I trial of stereotactic body radiation therapy (SBRT) for liver metastases. Int J Radiat Oncol Biol Phys. 2005;62(5):1371-8.

34. Robertson JM, McGinn CJ, Walker S, et al. A phase I trial of hepatic arterial bromodeoxyuridine and conformal radiation therapy for patients with primary hepatobiliary cancers or colorectal liver metastases. Int J Radiat Oncol Biol Phys. 1997;39(5):1087-92.

35. McGinn CJ, Ten Haken RK, Ensminger WD, Walker S, Wang S, Lawrence TS. Treatment of intrahepatic cancers with radiation doses based on a normal tissue complication probability model. J Clin Oncol. 1998;16(6):2246-52.

36. Dawson LA, McGinn CJ, Normolle D, et al. Escalated focal liver radiation and concurrent hepatic artery fluorodeoxyuridine for unresectable intrahepatic malignancies. J Clin Oncol. 2000;18(11):2210-8.

37. Ben-Josef E, Normolle D, Ensminger WD, et al. Phase II trial of high-dose conformal radiation therapy with concurrent hepatic artery floxuridine for unresectable intrahepatic malignancies. J Clin Oncol. 2005;23(34):8739-47.

38. Dawson LA, Normolle D, Balter JM, McGinn CJ, Lawrence TS, Ten Haken RK. Analysis of radiation-induced liver disease using the lyman NTCP model. Int J Radiat Oncol Biol Phys. 2002;53(4):810-21.

39. Bruix J, Sherman M. Management of hepatocellular carcinoma: An update. Hepatology. 2011;53(3):1020-2. 
40. Hussain SM, Semelka RC. Hepatic imaging: comparison of modalities. Radiol Clin North Am. 2005;43(5):929-47, ix.

41. Voroney JP, Brock KK, Eccles C, Haider M, Dawson LA. Prospective comparison of computed tomography and magnetic resonance imaging for liver cancer delineation using deformable image registration. Int J Radiat Oncol Biol Phys. 2006;66(3):78091.

42. Lujan AE, Larsen EW, Balter JM, Ten Haken RK. A method for incorporating organ motion due to breathing into 3D dose calculations. Med Phys. 1999;26(5):715-20.

43. Seppenwoolde Y, Shirato H, Kitamura K, et al. Precise and real-time measurement of $3 \mathrm{D}$ tumor motion in lung due to breathing and heartbeat, measured during radiotherapy. Int $\mathrm{J}$ Radiat Oncol Biol Phys. 2002;53(4):822-34.

44. Nehmeh SA, Erdi YE, Rosenzweig KE, et al. Reduction of respiratory motion artifacts in PET imaging of lung cancer by respiratory correlated dynamic PET: methodology and comparison with respiratory gated PET. J Nucl Med. 2003;44(10):1644-8.

45. Brock KK. Imaging and image-guided radiation therapy in liver cancer. Semin Radiat Oncol. 2011;21(4):247-55.

46. Kirilova A, Lockwood G, Choi P, et al. Three-dimensional motion of liver tumors using cine-magnetic resonance imaging. Int J Radiat Oncol Biol Phys. 2008;71(4):1189-95.

47. Keall PJ, Mageras GS, Balter JM, et al. The management of respiratory motion in radiation oncology report of AAPM task group 76. Med Phys. 2006;33(10):3874-900.

48. Herfarth KK, Debus J, Lohr F, et al. Extracranial stereotactic radiation therapy: set-up accuracy of patients treated for liver metastases. Int J Radiat Oncol Biol Phys. 2000;46(2):329-35.

49. Dawson LA, Brock KK, Kazanjian S, et al. The reproducibility of organ position using active breathing control (ABC) during liver radiotherapy. Int J Radiat Oncol Biol Phys. 2001;51(5):1410-21.

50. Eccles C, Brock KK, Bissonnette JP, Hawkins M, Dawson LA. Reproducibility of liver position using active breathing coordinator for liver cancer radiotherapy. Int J Radiat Oncol Biol Phys. 2006;64(3):751-59.

51. Shirato H, Shimizu S, Kitamura K, et al. Four-dimensional treatment planning and fluoroscopic real-time tumor tracking radiotherapy for moving tumor. Int $\mathrm{J}$ Radiat Oncol Biol Phys. 2000;48(2):435-42.

52. Thomas E, Chapet O, Kessler ML, Lawrence TS, Ten Haken RK. Benefit of using biologic parameters (EUD and NTCP) in IMRT optimization for treatment of intrahepatic tumors. Int J Radiat Oncol Biol Phys. 2005;62(2):571-78.

53. Kwon JH, Bae SH, Kim JY, et al. Long-term effect of stereotactic body radiation therapy for primary hepatocellular carcinoma ineligible for local ablation therapy or surgical resection. stereotactic radiotherapy for liver cancer. BMC Cancer. 2010;10:475.

54. Mendez Romero A, Wunderink W, Hussain SM, et al. Stereotactic body radiation therapy for primary and metastatic liver tumors: a single institution phase i-ii study. Acta Oncol. 2006;45(7):831-7.

55. Zhou ZH, Liu LM, Chen WW, et al. Combined therapy of transcatheter arterial chemoembolisation and three-dimensional conformal radiotherapy for hepatocellular carcinoma. Br J Radiol. 2007;80(951):194-201.

56. Seong J, Park HC, Han KH, Chon CY. Clinical results and prognostic factors in radiotherapy for unresectable hepatocellular carcinoma: a retrospective study of 158 patients. Int J Radiat Oncol Biol Phys. 2003;55(2):329-36.

57. Zeng ZC, Tang ZY, Fan J, et al. A comparison of chemoembolization combination with and without radiotherapy for unresectable hepatocellular carcinoma. Cancer J. 2004;10(5):307-16.

58. Li B, Yu J, Wang L, et al. Study of local three-dimensional conformal radiotherapy combined with transcatheter arterial chemoembolization for patients with stage III hepatocellular carcinoma. Am J Clin Oncol. 2003;26(4):e92-9.

59. Guo WJ, Yu EX, Liu LM, et al. Comparison between chemoembolization combined with radiotherapy and chemoembolization alone for large hepatocellular carcinoma. World J Gastroenterol. 2003;9(8):1697-701.

60. Koo JE, Kim JH, Lim YS, et al. Combination of transarterial chemoembolization and three-dimensional conformal radiotherapy for hepatocellular carcinoma with inferior vena cava tumor thrombus. Int J Radiat Oncol Biol Phys. 2010;78(1):180-7. 